\title{
DEVER DE CASA, ESPELHO DE DESIGUALDADES EDUCACIONAIS E SOCIAIS ${ }^{1}$
}

\author{
Tania de Freitas Resende*
}

RESUMO: Este artigo busca analisar, a partir de resultados de uma pesquisa microssociológica, diferenças e desigualdades de diversas ordens que são espelhadas na prática social de prescrição e realização dos deveres de casa, tanto no âmbito das famílias quanto no das escolas. Em alguns casos, trata-se de desigualdades mais explícitas, como as de condições de realização dos deveres e de acompanhamento pelas famílias. Em outros, trata-se de diferenças - por exemplo, entre as práticas socializadoras familiares, ou entre práticas curriculares das escolas - que se transformam em desigualdades à medida que configuram condições desiguais para estudantes colocados, no sistema escolar e na sociedade, em situação de competição. Em todos os casos, para além dos deveres em si, o que se coloca em questão são as condições de equidade/iniquidade do sistema educacional.

Palavras-chave: Deveres de Casa; Desigualdades; Educação.

\section{HOMEWORK, MIRROR OF EDUCATIONAL AND SOCIAL INEQUALITIES}

ABSTRACT: The aim of this article is to analyze, through the results of a micro-sociologic research, the various kinds of differences and inequalities that are reflected in the social practice of homework assignment and completion, within families as well as in schools. In some cases, inequalities are more explicit, as in the conditions for homework completion and family assistance. In other cases, there are differences - between family socializing practices or school curricular practices - that are transformed into inequalities when they establish unequal conditions to students that are in a competitive situation in school and society. In all cases, beyond homework, the equality/inequality conditions of the educational system are questioned.

Keywords: Homework; Inequalities; Education.

\footnotetext{
*Doutora em Educação pela Universidade Federal de Minas Gerais (UFMG); Professora Adjunto 2 da Faculdade de Educação da Universidade Federal de Minas Gerais (UFMG); Pesquisadora dos grupos Observatório Sociológico Família-Escola (OSFE) e Territórios, Educação Integral e Cidadania (TEIA). E-mail: taniaresende@ufmg.br
} 


\section{INTRODUC̣ÃO}

A prescrição de atividades escolares a serem realizadas fora do período de aulas e a utilização do espaço doméstico para esse fim - dando origem aos chamados "deveres de casa", "tarefas de casa", "lições para casa" - constitui, em nossa sociedade, uma prática tradicional, já incorporada à cultura escolar. Tal prática pressupõe a existência de dois espaços sociais especializados - o doméstico e o escolar -, implicando, ao mesmo tempo, a diferenciação de funções e a comunicação entre eles. Por meio dela se instaura uma teia de relações sociais (HENRIQUES, 2007) que interliga professores, alunos, pais e outros agentes envolvidos no acompanhamento aos deveres, tais como parentes, vizinhos, professores particulares. Nesse sentido, o dever de casa constitui um forte vínculo de interação entre família e escola (CARVALHO, 2001) e coloca cotidianamente em questão a divisão do trabalho educacional entre essas duas instâncias socializadoras.

Com base em Ariès (1981, p. 159), pode-se afirmar que as tarefas de casa não configuram uma prática educacional recente, sendo encontradas, nos tratados de educação do século XVII, referências insistentes aos deveres dos pais, entre outros, quanto à “[...] supervisão dos estudos, à repetição das lições, quando a criança vinha dormir em casa [...]”. Entretanto, é a partir das últimas décadas do século $\mathrm{XX}$, no seio de um movimento crescente de imbricação entre família e escola, disseminando-se uma "ideologia da colaboração" entre as duas instituições (NOGUEIRA, 2005), em um contexto de competitividade econômica e de valorização do capital escolar, que se vai observar uma ênfase cada vez maior na prescrição dos deveres de casa e em seu acompanhamento pelas famílias, como fatores de sucesso escolar (CARVALHO; BURITY, 2005).

Apesar disso e de sua forte presença no cotidiano das escolas e das famílias, o dever de casa tem sido pouco focalizado como objeto específico de estudo das ciências da educação. Paula (2000) observa uma naturalização dessa prática pedagógica, legitimada a partir das prescrições didáticas e, portanto, pouco problematizada. Glasman (2005) constata uma defasagem entre a abundante reflexão sobre o tema no âmbito do senso comum e das publicações comerciais, de um lado, e o número limitado de pesquisas científicas, de outro. Carvalho (2004) verifica que o dever de casa aparece mais frequentemente como um tópico periférico em análises sobre 
rendimento acadêmico e relação família-escola, sem que seja tomado, em si, como objeto de investigação. Deslandes (2009), em obra que reúne trabalhos de pesquisadores de diferentes países, evidencia que várias preocupações relativas ao dever de casa são comuns às distintas nações e reconhece a necessidade de ampliar os conhecimentos científicos sobre o assunto.

Neste trabalho, parte-se do pressuposto de que as práticas e concepções relativas ao dever de casa ganham importância, como objeto de análise, para além de sua vinculação específica aos resultados do processo pedagógico, especialmente na medida em que podem espelhar outros aspectos centrais desse processo, tais como: as diferentes matrizes curriculares e seus fundamentos; a relação com o saber, com o aprender e com o trabalho escolar; as relações entre família e escola e a própria função social da última. A imagem do "espelho" aqui não evoca, evidentemente, uma reprodução perfeita, mas sim a possibilidade de se visualizar tais aspectos do processo educacional ao "olhar" para o dever de casa - o que se torna possível uma vez que este "[...] está na encruzilhada de numerosos fenômenos constitutivos do mundo escolar e de suas relações com o resto da sociedade [...]" (RAYOU, 2009, p. 10, tradução minha).

Assim, a pesquisa em pauta neste texto tomou como objeto as concepções e as práticas escolares e familiares em relação ao dever de casa, focalizando dois grupos sociais distintos, recortados especificamente dentro das camadas médias e das camadas populares. A investigação buscou entrever, por meio das tarefas de casa, aspectos ligados às relações família-escola e ao currículo escolar, fundamentando-se, para isso, nos ramos da sociologia da educação que vêm se dedicando ao estudo dessas duas temáticas.

O trabalho de campo realizou-se em duas etapas, com turmas de $3^{a}$ série de três escolas de Belo Horizonte: dois colégios privados, laicos, de prestígio na comunidade, que atendem a alunos de camadas médias ${ }^{2}$ (aqui chamados de Colégios Lua e Estrela); e uma escola pública estadual, com alunos de camadas populares ${ }^{3}$, moradores de um dos maiores aglomerados da cidade (Escola Sol) ${ }^{4}$. Na primeira etapa, buscando-se apreender as concepções e as práticas escolares em relação ao dever de casa, foram realizadas observações em sala de aula (em uma turma de $3^{\text {a }}$ série de cada escola) ${ }^{5}$, análise de documentos e entrevistas com as profissionais (professoras e coordenadoras pedagógicas). Na segunda etapa, para investigar as concepções e práticas familiares, aplicou-se um questionário aos pais de alunos da $3^{\mathrm{a}}$ 
série $^{6}$ e realizaram-se entrevistas semiestruturadas com 10 famílias de cada escola, perfazendo, no total, 30 entrevistas ${ }^{7}$.

Selecionaram-se, para o presente trabalho, resultados que evidenciam diferenças e desigualdades ${ }^{8}$ de diversas ordens, espelhadas na prática social de prescrição e realização dos deveres de casa, tanto no âmbito das famílias quanto no das escolas. Em alguns casos, são desigualdades mais explícitas, como as de condições materiais de realização dos deveres ou as assimetrias nos níveis de escolaridade dos responsáveis pelo seu acompanhamento. Em outros, trata-se, em princípio, de diferenças - por exemplo, entre as práticas socializadoras familiares, ou entre práticas curriculares das escolas - que se transformam, entretanto, em desigualdades, à medida que configuram condições desiguais para estudantes que, em última análise, são colocados, no sistema escolar e na sociedade, em situação de competição.

Dessa forma, a presente discussão busca articular temáticas relevantes na sociologia da educação - as relações entre desigualdades escolares e sociais, o currículo escolar e a relação família-escola - a partir de uma abordagem microssociológica cuja maior contribuição parece ser a de evidenciar processos sociais cotidianos por meio dos quais essas diferentes dimensões da prática pedagógica se combinam, de modos muitas vezes sutis e pouco considerados, na reprodução das hierarquias sociais.

\section{DIFERENC̣AS NO ÂMBITO DAS FAMÍLIAS: DESIGUALDADES EM RELAC̣ÃO ÀS EXIGÊNCIAS ESCOLARES}

No conjunto de reflexões existentes a respeito dos deveres de casa, não há ineditismo em apontar as desigualdades no tocante às condições materiais e simbólicas de sua realização pelos estudantes e de seu acompanhamento, pelos pais ou adultos responsáveis, no contexto doméstico. Segundo Meirieu (1998, p. 10), “[...] todo o trabalho que é sistematicamente mandado para fazer em casa é, na realidade, um trabalho remetido para a desigualdade: desigualdade de condições de habitação, mas também, e sobretudo, de ambiente cultural [...]”. Autores como Glasman (2005) e Rayou (2009) enfatizam a diversidade de estratégias e condições familiares para o acompanhamento aos deveres, destacando as dificuldades das famílias de camadas populares. No contexto brasileiro, Carvalho (2001, 
2004) e Carvalho, Nascimento e Paiva (2006) chamam a atenção para para o fato de que a ênfase na prescrição de deveres de casa e no acompanhamento parental pode ter graves efeitos no que se refere a um projeto de equidade educacional, ao converter diferenças de capital cultural, econômico, social, em vantagens ou desvantagens escolares.

Ainda assim, considera-se relevante discutir alguns resultados da presente pesquisa que se referem às desigualdades espelhadas na prática do dever de casa, no âmbito das famílias, tanto a fim de explorar nuances nem sempre enfatizadas, quanto no sentido de contribuir para o aprofundamento da problematização das relações entre deveres de casa e desigualdades sociais.

A esse respeito, um primeiro achado deste estudo é que, entre as famílias dele participantes, as desigualdades se manifestam no quadro de um grande consenso em relação à importância dos deveres de casa e de seu acompanhamento pelos pais ou responsáveis. As mães e os pais investigados, tanto das camadas médias quanto das populares, foram unânimes, nos questionários e nas entrevistas, em defender os deveres como importantes e necessários, bem como em argumentar favoravelmente ao envolvimento da família na vida escolar da criança, em geral, e no apoio à realização das lições, mais particularmente. Sem prejuízo das diversas questões que podem ser levantadas no sentido de problematizar esse consenso (RESENDE, 2006a), e sem pretender generalizá-lo, cumpre ressaltar que, diante dele, as diferenças entre as situações familiares são vividas como desigualdades que engendram "[...] experiências dolorosas do mundo social [...]" (BOURDIEU, 1998, p. 735), mais ou menos visíveis e/ou explicitadas pelos próprios sujeitos. Em outras palavras: se o dever de casa é considerado favorecedor do desempenho escolar e se o acompanhamento parental a ele é visto como um dos fatores de sua eficácia, isso objetivamente coloca as diferentes famílias em posições desiguais diante do mercado escolar, já que elas não dispõem de condições materiais e culturais idênticas para fazer face a esse papel; e tal desigualdade é tanto mais vivida como sofrimento quanto mais as famílias compartilham dessa concepção que coloca a escolaridade, os deveres de casa e o acompanhamento parental como valores. Tal sofrimento resulta, portanto, do fato de que, não sendo indiferentes aos valores escolares, as famílias em questão nem sempre encontram, em suas dinâmicas internas, os recursos necessários para corresponder a eles de modo satisfatório. 
Especialmente em se tratando das camadas populares, destacar tal constatação é importante na medida em que o argumento da omissão parental, apesar de negado e tratado como mito por diversos estudos (LAHIRE, 1997; VIANA, 2000; NOGUEIRA; ABREU, 2004), ainda é utilizado com frequência, pelos educadores, para explicar baixos desempenhos dos alunos. Por exemplo, em sua entrevista, Imaculada ${ }^{9}$, professora da turma investigada na escola Sol, enfatizou várias vezes, em relação ao fato de que muitas crianças não faziam os deveres de casa regularmente ${ }^{10}$, que a "culpa" ou responsabilidade principal por esse fato era das famílias que, segundo ela, "não estão nem ấ". Os resultados obtidos na pesquisa, ao contrário, corroboram os estudos citados, ao indicar a importância atribuída pelas famílias investigadas ao dever de casa e à escolaridade dos filhos, de forma geral.

Cabem, aqui, duas ressalvas. Em primeiro lugar, o material empírico deste estudo, obtido por meio de entrevistas ou de questionários, foi o discurso dos pais ou responsáveis, o qual, é claro, não necessariamente retrata com fidedignidade sua prática concreta, sendo necessário levar em conta os possíveis efeitos, sobre esse discurso, da situação de pesquisa como relação social (BOURDIEU, 1998). Em segundo lugar, os dados obtidos não estão sendo tomados como estatisticamente representativos de toda a população-alvo (no caso, o universo de famílias da Escola Sol), já que os procedimentos metodológicos não foram organizados com tal objetivo. Além disso, no caso do questionário, o qual continha cinco páginas de questões fechadas, uma hipótese levantada foi a de que a própria disponibilidade em responder a ele tenha sido maior entre os pais que possuem disposições e/ou condições mais favoráveis à participação na vida escolar dos filhos. Segundo esse raciocínio, pode ser que haja, realmente, casos de "omissão parental" não representados no grupo de pais que participaram efetivamente da pesquisa.

Não obstante tais ressalvas, uma série de fatores contribui para tomar como significativos os dados obtidos, embora, evidentemente, sem generalizá-los. Um deles é o próprio índice de resposta ao questionário na Escola Sol (66\%), bastante expressivo (e o maior entre as três escolas investigadas), indicando certa mobilização das famílias para atender ao que era, de resto, uma solicitação escolar. Um segundo fator é a consonância com outros estudos, como os já citados, que questionam o mito da omissão 
parental, também a partir de dados empíricos. Finalmente, a triangulação de dados (oriundos do questionário, das entrevistas, das observações em sala de aula) indicou coerência na interpretação de que se está diante de um grupo de famílias que, de forma geral, atribuem importância ao dever de casa e à escolaridade dos filhos e buscam mobilizar as estratégias possíveis para apoiá-los, fazendo-o muitas vezes, entretanto, a partir de uma situação social em que tais estratégias se mostram limitadas e insuficientes.

Um exemplo é o dos materiais disponíveis em casa para a realização dos deveres (Tabela 1). Os únicos materiais em relação aos quais não se constataram grandes desigualdades (no que tange à disponibilidade na residência) entre as famílias das escolas privadas e da pública foram os dicionários e os jornais e revistas. Quanto aos primeiros, sabe-se que fazem parte do material recebido gratuitamente pelos alunos das escolas públicas, por meio do PNLD - Programa Nacional do Livro Didático, do Ministério da Educação. No caso dos jornais e revistas, trata-se de materiais de mais fácil acesso que, conforme se apurou nas entrevistas, frequentemente as mães e alguns pais da escola Sol traziam de seu ambiente de trabalho (no caso de empregadas domésticas, faxineiras, porteiros e outros), para serem usados pelos filhos nas tarefas de casa. Esse dado contribui para confirmar o interesse desses pais em apoiar, no âmbito de suas possibilidades, a escolaridade dos filhos e a realização dos deveres. O que ocorre é que tais possibilidades são, em geral, de menor alcance que as dos pais mais favorecidos. Os dados relativos ao uso do computador e da internet (Tabela 1) indicam claramente essa desvantagem, podendo-se, quanto a esse aspecto, discutir novas configurações das desigualdades escolares e sociais, as quais, no contexto de uma "sociedade da informação", vêm assumindo, entre outras formas, a da exclusão digital (RESENDE, 2006b).

Observaram-se, ainda, outras formas de desigualdade que incidiam mais diretamente nas possibilidades de acompanhamento dos deveres de casa pelos pais ou responsáveis. A mais evidente foi o capital cultural familiar, aqui representado pelo seu aspecto institucionalizado ${ }^{11}$, ou seja, pelo nível de escolaridade dos pais (Tabela 2). Constata-se, nesse caso, uma inversão completa entre as escolas Lua e Estrela - nas quais predominavam largamente os pais e mães formados em nível superior, grande parte com pós-graduação - e a escola Sol, em que a grande maioria somente cursou o ensino fundamental, muitos dos quais apenas em sua primeira fase (até a antiga $4^{\mathrm{a}}$ série). 


\section{Tabela 1}

Materiais disponibilizados no domicílio para a realização dos deveres (\% de incidências em relação ao total de questionários respondidos)

\begin{tabular}{c|c|c|c|c|c|c}
\multirow{2}{*}{ Escolas } & \multicolumn{6}{|c}{ Materiais } \\
\cline { 2 - 7 } & Dicionários & Enciclopédias & $\begin{array}{c}\text { Outros } \\
\text { livros }\end{array}$ & $\begin{array}{c}\text { Revistas e } \\
\text { jornais }\end{array}$ & Computador & Internet \\
\hline Estrela & 93 & 64 & 50 & 87 & 66 & 87 \\
\hline Lua & 95 & 69 & 51 & 85 & 74 & 82 \\
\hline Sol & 86 & 14 & 37 & 91 & 5 & 0 \\
\hline
\end{tabular}

Fonte: Questionário respondido pelas famílias - 2004.

\section{Tabela 2}

Escolaridade dos pais dos alunos $(\%$ em relação ao total de questionários respondidos)

\begin{tabular}{|c|c|c|c|c|c|c|c|c|c|c|}
\hline \multirow[t]{3}{*}{ Escola } & \multicolumn{10}{|c|}{ Porcentagem de pais conforme o maior nível de ensino concluído* } \\
\hline & \multicolumn{2}{|c|}{$\begin{array}{c}\text { Ensino } \\
\text { fundamental }\end{array}$} & \multicolumn{2}{|c|}{ Ensino médio } & \multicolumn{2}{|c|}{$\begin{array}{l}\text { Ensino } \\
\text { superior }\end{array}$} & \multicolumn{2}{|c|}{$\begin{array}{c}\text { Pós- } \\
\text { graduação* * }\end{array}$} & \multicolumn{2}{|c|}{$\begin{array}{c}\text { Não } \\
\text { responderam } \\
\text { ou anularam }\end{array}$} \\
\hline & Pai & Mãe & Pai & Mãe & Pai & Mãe & Pai & Mãe & Pai & Mãe \\
\hline Estrela & - & 2 & 26,5 & 30,5 & 51 & 44,5 & 22 & 22 & & 1 \\
\hline Lua & 2,5 & - & 13 & 20,5 & 48,5 & 59 & 36 & 20,5 & - & - \\
\hline Sol** & 77 & 82 & 5 & 14 & - & - & - & - & 18 & 4 \\
\hline
\end{tabular}

Fonte: Questionário respondido pelas famílias - 2004. * No caso da escola Sol, a escolaridade indicada não corresponde, necessariamente, à conclusão do nível de ensino, estando distribuída ao longo dele. Por exemplo, $44 \%$ dos pais e 30\% das mães cursaram apenas até a $4^{\mathrm{a}}$ série ou menos.

* * Incluindo especialização, pós-graduação latu sensu, mestrado ou doutorado.

Nas entrevistas, mães de alunos da Escola Sol que haviam enfatizado a importância do acompanhamento dos deveres pela família expressaram sofrimento por não se sentirem à altura dessa tarefa:

[...] en fico perdida também, porque não sei como fazer. [...] Precisa ver... en desespero. [...] Porque eu fiquei 21 anos sem estudar. Então era difícil lembrar as coisas que eles tavam pedindo pra fazer... e lembrar assim, no estalo. Eu falava: "Isabela, cê tá entendendo o que que é pra fazer aqui?" [A menina respondia] "Não, mãe". [A mãe perguntava ao outro filho:] "Rafael, cê tá entendendo?" [Ele respondia] "Não, mãe". 
"O que que é pra fazer então?” Nem eles sabia. Então ficava difícil, aí não fazia e ela [a professora] mandava os bilhete pra mim. Falando que era para mim ter um pouco mais de... esforçar um ponco mais... olhar mais os cadernos... tava ficando incompleto...

(Fernanda, 36 anos, 6 filhos, agente de saúde, cursou até a $7^{a}$ série e na época da pesquisa frequentava a Educação de Jovens e Adultos. Entrevista de pesquisa, 2004.)

Também aqui cabe observar que, apesar da baixa escolaridade, a maior parte dos pais participantes da pesquisa, na Escola Sol, afirmava acionar as estratégias que estavam ao seu alcance para acompanhar os deveres dos filhos. Como demonstra a Tabela 3, a maioria deles declarou ajudar na busca de informações, verificar se os deveres estão completos, exigir capricho e organização, exortar os filhos à realização das tarefas, conferir o dever depois de pronto. Entretanto, a comparação com os dados relativos às escolas Estrela e Lua, na mesma tabela, ajuda a evidenciar como as desigualdades vão se revelando, também, em relação a aspectos mais sutis. Assim, com exceção da ajuda na busca de informações e da conferência do dever, os outros tipos de auxílio mencionados pelos pais ou responsáveis da escola Sol constituem justamente os menos citados pelas famílias das escolas de camadas médias. Estas indicam, predominantemente, tarefas de apoio e suporte à atividade da criança, incluindo o esclarecimento de dúvidas.

Uma provável hipótese explicativa para essas diferenças é o baixo nível de escolaridade dos pais da escola Sol, que dificulta o desempenho de tarefas como o esclarecimento de dúvidas. Além desta, pode-se levantar a hipótese da existência, nas escolas Lua e Estrela, de um maior nível de autonomia das crianças quanto à realização dos deveres de casa, pela internalização de hábitos e disposições em relação a eles - o que ocorreria em menor grau na escola Sol, como fazem crer, entre outros dados, os altos índices de não cumprimento dos deveres pelos alunos da turma observada nessa escola. Em estudos com camadas populares, Thin (1998, 2006) identifica, entre os pais desse meio, um modo de autoridade baseado na pressão exterior, realizada caso a caso, isto é, em situações específicas e contextualizadas, mais do que no estímulo à internalização de regras e princípios morais generalizáveis para diversas situações, numa perspectiva de autocontrole. $\mathrm{O}$ autor destaca que tal modo de autoridade se distancia das exigências escolares atuais, voltadas para a autonomia e a autorregulação do comportamento de acordo com as regras da vida escolar e social. 


\section{Tabela 3}

Tarefas realizadas com maior frequência pelo adulto que acompanha o dever de casa (\% de incidências em relação ao total de questionários respondidos em cada escola*)

\begin{tabular}{c|c|c|c} 
Tarefas & Estrela & Lua & Sol \\
\hline a) Lembrar a criança do dever de casa e assegurar que o faça & 38 & 38 & 63 \\
\hline b) Verificar se os deveres estão completos & 58 & 38 & 74 \\
\hline $\begin{array}{c}\text { c) Controlar o tempo que a criança passa trabalhando, } \\
\text { apressá-la, evitar que desvie a atenção }\end{array}$ & 36 & 41 & 9 \\
\hline d) Exigir capricho e organização nos trabalhos & 50 & 61 & 74 \\
\hline e) Esclarecer dúvidas sobre o enunciado das questões & 73 & 82 & 42 \\
\hline f) Esclarecer dúvidas sobre o conteúdo estudado & 43 & 41 & 23 \\
\hline $\begin{array}{c}\text { g) Fornecer materiais de consulta ou de apoio } \\
\text { h) Ajudar na busca de informações em livros, revistas, } \\
\text { Internet, enciclopédias, etc. }\end{array}$ & 78 & 67 & 14 \\
\hline i) Conferir o dever depois de pronto e sugerir correç̃̃es & 71 & 85 & 79 \\
\hline j) Outra & 3 & 67 & 63 \\
\hline
\end{tabular}

Fonte: Questionário respondido pelas famílias - 2004. *A soma das porcentagens ultrapassa os $100 \%$ em cada escola porque nesta questão podia-se marcar mais de uma opção.

Emerge, nesse ponto, um outro tipo de desigualdade, referente à maior ou menor consonância entre os processos de socialização familiares e escolares (LAHIRE, 1997; THIN, 1998, 2006). Assim, características dos processos de socialização que, em princípio, configurariam a diversidade dos grupos familiares transformam-se em desigualdade à medida que esses grupos se confrontam com um modo de socialização dominante - o modo escolar, diante do qual os alunos são colocados em situação de competição, no que se refere à hierarquização de seus desempenhos acadêmicos. Tal constatação pode ser feita tanto na comparação entre camadas médias e populares, quanto no estudo de diferentes famílias no interior de cada um desses estratos sociais.

A título de exemplo, cabe mencionar a entrevista com Magda, mãe de Renato, aluno do Colégio Estrela ${ }^{12}$. $\mathrm{Na}$ época da pesquisa, o filho passa por dificuldades na escola; segundo a mãe, o motivo é que ele "tem preguiça”, quer terminar depressa as tarefas escolares (tanto as de casa quanto as das aulas, inclusive as próprias avaliações) para brincar. Quanto ao dever de casa, "nunca foi de pegar e fazer com gosto", por iniciativa própria. A 
mãe já havia mobilizado diversas estratégias para apoiar a escolaridade dele, como, por exemplo, contratar professores particulares para acompanhar os deveres e dar reforço escolar, ou mudar o horário de trabalho para fazer ela mesma esse acompanhamento. Entretanto, é possível depreender, da entrevista, alguns elementos do processo de socialização familiar que parecem pouco favorecedores da construção, pelo menino, de certas disposições facilitadoras da adequação às exigências escolares.

Um aspecto em que isso se evidencia é a relação com a cultura escrita. Magda afirma que "detesta ler", não tem nenhum hábito de leitura. A família compra regularmente as revistas Veja ou Istoé e um jornal aos domingos, mas apenas o marido os lê, e não de forma sistemática. Renato também não tem hábito de leitura, segundo a mãe, embora goste de assistir aos jornais na televisão e seja, nas palavras dela, "um menino culto", que sabe falar sobre os mais diversos assuntos.

Pode-se ainda identificar, no discurso da mãe de Renato, certa tensão entre o "brincar" e o trabalho escolar, visto como investimento formativo para o futuro. O pai do menino já propôs várias vezes transferi-lo de escola, por considerar que o filho "não está dando conta" das exigências do colégio Estrela ${ }^{13}$ e não tem tempo para brincar. A mãe não concorda com essa transferência, mas, ao acompanhar as tarefas de casa, prefere, por vezes, fazer as atividades, especialmente as de pesquisa, para o filho copiar, argumentando que ele ficaria sem tempo para brincar, caso fosse fazer tudo sozinho.

Magda também demonstra ambiguidade em relação ao dever de casa. Diz que ele é muito importante para o desenvolvimento da criança, mas reforça, em vários momentos, que na escola Estrela a quantidade de deveres é excessiva; já em outros momentos, afirma que deve ser assim mesmo, pois o nível alto de exigência é necessário para a formação da criança. Quando indagada se matricularia seu filho em uma escola que não prescrevesse deveres de casa, diz que não - procuraria uma escola ainda mais exigente que o Colégio Estrela.

Enfim, a entrevista sinalizou certa contradição entre uma escolarização de excelência, que a mãe parece considerar que "deve desejar" para o filho, e alguns traços do ambiente socializador familiar, que indicam uma orientação mais lúdica do que ascética, mais voltada para a oralidade e o saber-fazer do que para a escrita e os saberes por ela mediatizados. Diante 
do desejo de proporcionar a melhor preparação do filho para o futuro do vestibular e da competição profissional e face aos modelos socialmente dominantes do que seja uma boa preparação, a mãe não consente na transferência de escola proposta pelo pai, mas vive, no cotidiano, as tensões derivadas da tentativa de conciliação entre duas lógicas socializadoras muitas vezes confrontantes. Assim, se na comparação com as famílias da escola Sol a situação de Renato se mostra privilegiada, já em relação a outras famílias da escola Estrela, mais próximas culturalmente da lógica socializadora representada pela escola, tal situação é de desvantagem.

A partir do exposto, conclui-se que interpretar as desigualdades espelhadas no dever de casa com foco nos padrões de socialização familiares e escolares mostra-se uma perspectiva capaz de refinar as análises sobre o tema, contribuindo para a discussão a respeito dos processos de escolarização e dos fatores de influência no desempenho escolar. Pode-se, dessa forma, verificar como tais desigualdades vão se construindo também no interior de cada grupo social, a partir das dinâmicas e processos internos às famílias.

\section{DIFERENÇAS NO ÂMBITO DAS ESCOLAS: OFERTAS ESCOLARES DESIGUAIS}

Carvalho, Nascimento e Paiva (2006, p. 345) lembram, apropriadamente, que a eficácia do dever de casa como recurso pedagógico depende não apenas da motivação do aluno e do apoio familiar, aspectos frequentemente ressaltados nos discursos, mas também do planejamento e da prática pedagógica da escola, os quais constituem, para as autoras, um "ponto silenciado", que precisa ser mais investigado. De fato, os dados obtidos nesta pesquisa evidenciam, além das desigualdades ligadas às famílias, aquelas que derivam das práticas curriculares das instituições de ensino.

Durante as observações em sala de aula constatou-se, nas escolas de camadas médias (Colégios Estrela e Lua), a maior adesão dos alunos às práticas em torno do dever de casa, havendo poucos casos de crianças que não o faziam ou que o deixavam incompleto. Já na turma observada na escola Sol havia, especialmente na disciplina de Língua Portuguesa, um grande problema instalado em relação às tarefas de casa, sendo frequentes os dias em que uma grande parte dos alunos simplesmente não as fazia. Verificou-se que, para compreender essa diferença, além de possíveis fatores 
individuais e/ou familiares - que eram apontados pelas professoras da escola Sol como principais causas do problema -, tornava-se necessário considerar, também, as concepções e as práticas de cada docente em relação ao dever de casa e suas relações com a proposta pedagógica de cada escola ${ }^{14}$.

Nos colégios Lua e Estrela, observou-se uma política de valorização do dever de casa, expressa em diversos aspectos. Há, em documentos oficiais das duas escolas, diretrizes claramente explicitadas em relação a essa prática ${ }^{15}$. Além disso, pode-se afirmar que o dever de casa é também valorizado pela sua prescrição sistemática, pelo modo como, em geral, é proposto (com explicações sobre as questões, esclarecimentos sobre as conexões entre o dever e as outras atividades, exortações de estímulo à sua realização - "vocês vão gostar", "está muito fácil" -, etc.), pelo tipo de atividade que envolve (havendo considerável variação nos tipos de tarefas ou de questões propostas nos diversos deveres), pela forma participativa de discuti-lo em sala de aula. Ele ocupa um importante lugar no currículo vivido, desempenhando simultaneamente vários papéis.

Alguns desses papéis são os mais tradicionalmente atribuídos a essa prática escolar, tais como: fixação do aprendizado, formação de hábitos de estudo, etc. Entretanto, destacam-se também, nessas duas escolas, outras funções atribuídas ao dever de casa. Uma delas, enfatizada pela professora Raquel (colégio Estrela), em sua entrevista, é a de ampliação e extrapolação do trabalho realizado em sala de aula. Nas observações nessas escolas, verificou-se que, se em alguns deveres as questões propostas eram tipicamente de revisão e fixação de conteúdos, outras vezes o tipo de questão visava apresentar desafios, oportunizar o desenvolvimento de argumentos, a ampliação de pontos de vista, a construção de raciocínios diversificados, a conexão com a vida da criança ou com assuntos da atualidade. Nas entrevistas, tanto Raquel quanto Beth (a última, professora do Colégio Lua) valorizaram esse tipo de tarefa, em oposição ao que chamaram de deveres "tradicionais", "repetitivos", "baseados em modelos" e em questões "diretas".

As tarefas de casa que essas professoras consideram "criativas", "desafiadoras" e "argumentativas", por sua vez, são indissociáveis, como afirma Raquel, do trabalho realizado em sala de aula. Este inclui uma "correção coletiva" dos deveres, realizada sistematicamente, de modo muito participativo, estimulando o debate, o confronto de pontos de vista, de argumentos e de estratégias distintas de solução de problemas. Durante 
essa correção, os alunos têm muitas oportunidades de serem ouvidos; em geral, suas contribuições são valorizadas e seus erros são tratados como hipóteses válidas. Investe-se, nesse momento, uma parte significativa da aula (em torno de uma hora, podendo chegar a mais).

Tais características da abordagem dada ao dever de casa podem ser em parte observadas no trecho a seguir, extraído do Diário de Campo da escola Lua ${ }^{16}$ :

[A professora corrige o dever de Matemática, baseado em uma reportagem da revista Veja, intitulada "A guerra dos preços", que apresentava preços de passagens aéreas Rio-São Paulo, em diferentes empresas.]

A professora explora a tabela com os alunos, fazendo perguntas. Pede para uma criança ler a primeira questão. Paulo lê: "2 pessoas compraram passagens pela Vasp. Qual a economia em relação às passagens pela Varig?”. A professora pergunta como fizeram para encontrar a resposta. A aluna Patricia diz que é preciso olhar o preço nas duas companbias e subtrair.

Professora - Quando subtrair eu vou encontrar o quê?

Patrícia-A diferença...

Carol-Mas primeiro tem que somar, porque são duas pessoas.

Professora - Ah, a Carol tá falando... O preço da tabela é pra 1 ou pra 2 pessoas?

Alguns alunos - Uma!

Professora - Então tenho que fazer o quê?

Alguns alunos dizem "somar", outros "multiplicar".

P - Vou ter duas formas de fazer isso. Carol, quer fazer sua forma no quadro?

Carolina vai à lousa, calcula o preço total das passagens primeiro na Varig, depois na Vasp e em seguida faz a subtração.

Durante o trabalho, a professora vai fazendo comentários e novas perguntas aos alunos. Quando Carolina termina, ela indaga:

- Alguém fez esse problema de outra maneira? Alguém pensou diferente?

A professora insiste na pergunta, até afirmar que bá outra forma de resolver e Gabriel dir que acha que sabe qual é. A professora vai fazendo perguntas, conduzindo os alunos a uma segunda forma de resolução (faz̧er a subtração primeiro, depois multiplicar por dois). Clara diz que tinha feito desse jeito. A professora fala que ela precisa confiar mais nas coisas que far. Diz que existem vários jeitos de resolver um problema e que na prova, às vezes, os alunos usam formas que ela própria não imaginaria. Continua 
corrigindo o dever por meio de perguntas, estimulando as crianças a expressar comentários e dúvidas.

(Diário de Campo - turma de $3^{a}$ série da Escola Lua - 5/3/2004).

Nesse contexto, o dever de casa, mais do que uma forma de fixar conteúdos ou de ocupar a criança, apresenta-se como um tempo de trabalho extraclasse que ajuda a compor o tempo da aula, dando fluência ao trabalho pedagógico e potencializando a carga horária especificamente letiva. Tendo em vista o tempo significativo despendido em estratégias eminentemente coletivas, como debates, discussões e atividades em grupo, o dever de casa assume tanto a função de ensejar o trabalho individual - e, portanto, a emergência de dúvidas, a construção pessoal de argumentos e raciocínios -, quanto também a de subsidiar as aulas e "adiantar" o seu andamento, realizando-se em casa atividades individuais que servirão de base para discussões em classe.

Cabe ressaltar que, depois da "correção coletiva", os deveres ainda são, com alguma regularidade, revisados pelas professoras, que dão retornos individualizados aos alunos. Todos esses elementos parecem valorizar o dever de casa como importante componente da vida escolar, criando um contexto favorável à adesão a ele.

Evidentemente, a continuidade entre as lógicas socializadoras familiares e escolares, observada com maior frequência nos dois colégios do que na Escola Sol, é também um fator decisivo para explicar tal "adesão". Observa-se que, mesmo com essa abordagem que se pretende "desafiadora e interativa", os deveres continuam sendo, essencialmente, modalidades de trabalho escolar, o qual requer determinadas disposições ou pressupõe a mobilização de certos recursos pessoais ${ }^{17}$ que não são independentes da socialização familiar ${ }^{18}$. Entretanto, considerando que a escola também é espaço socializador e, portanto, formador (e/ou transformador) de disposições, parece imprescindível levar em conta, nessa explicação, as concepções e as práticas curriculares ligadas ao dever de casa.

Com relação à escola Sol, constatou-se que, além da maior dissonância, em termos gerais, entre as exigências escolares e as lógicas e/ou condições familiares, as concepções e práticas das professoras em relação ao dever de casa não parecem, também, favorecer a adesão dos alunos. Nas entrevistas com as duas docentes, os deveres são tratados como "obrigações do aluno", voltadas para a "fixação", "memorização" 
ou "reforço" do que é visto em sala, com um enfoque de treinamento. São também apontados como serviço ou trabalho do aluno, em troca do qual ele receberá o "pagamento" da progressão no final do ano: "Eu considero assim, como a criança não tem aquele trabalho fixo de salário e tudo, [...] como se fosse um trabalho que ele tem que produzir, pra no final do ano ele ir embora pra série seguinte" (professora Regina, escola Sol). As atividades que constituem os deveres correspondem, em geral, a esse objetivo de fixação e treinamento, apresentando questões de resposta mais objetiva, baseadas em modelos já desenvolvidos nas aulas, frequentemente repetitivas, com pouco espaço para a autoexpressão ou o desenvolvimento de hipóteses e estratégias pessoais diante dos problemas.

O tratamento dado ao dever em sala de aula é, também, bastante diferente do observado nos colégios Estrela e Lua. Embora haja uma norma verbal, na escola, de que os deveres devem ser dados diariamente ${ }^{19}$, não é isso o que efetivamente acontece, havendo dias em que nenhuma das duas professoras ${ }^{20}$ propõe atividades para casa. As correções coletivas, quando realizadas, consistem basicamente na enunciação das respostas corretas. Tal enunciação é feita de três formas: a professora dirige perguntas para toda a turma, a serem respondidas "em coro"; a professora chama apenas uma criança para responder cada exercício, confirmando ou corrigindo sua resposta; ou então a própria professora resolve o exercício no quadro. Em todos os casos, há pouco espaço para um maior número de crianças participarem e explicitarem suas hipóteses e pontos de vista. A atividade, como as demais, desenvolve-se no contexto de uma relação pedagógica marcada pelo disciplinamento exterior, por meio de constantes admoestações, realizadas, várias vezes, com alto grau de animosidade. A professora de Matemática (Regina) tem uma sistemática de correção individual dos cadernos dos alunos, a qual, frequentemente, substitui a correção coletiva. A professora Imaculada às vezes faz essa correção individual e, poucas vezes, realiza a coletiva. Registraram-se, ainda, algumas situações em que os deveres de casa não foram corrigidos em nenhum momento, individual ou coletivamente.

O trecho do Diário de Campo da escola Sol pode ilustrar, em parte, a dinâmica das aulas nesse contexto: 
Chego à sala às 7h20. Os alunos estão assentados, mas a professora Imaculada ainda não iniciou nenhuma atividade. Ouco-a repreendendo a turma, em tom áspero. Aguardo sua autorização e entro. A professora diz aos alunos:

- Caderno de Para Casa. Coloca aqui [indicando sua mesa] pra dar o visto.

Poucos alunos se levantam para entregar o caderno. Imaculada vai chamando pelo nome os que não se levantam:

- André, Para Casa!

- Esqueci em casa!

- Ah, esqueceu em casa? Eu não dou aula para a casa!

Vai chamando outras crianças. Várias dizem que esqueceram. A professora repreende a turma:

- De 26 alunos que estão aqui hoje, só 12 cadernos. Essa turma... tá terrivel no Para Casa. Eu vou desistir. Vocês não querem saber de nada! Todo dia é assim, esqueceu, não teve tempo! Eu tô cansada, desanimada!

A professora pede que eu dê visto nos cadernos e começa a passar no quadro um texto para os alunos copiarem. O dever de casa não é corrigido por ela, nem no quadro e nem individualmente. [...]

Depois do recreio, a professora Regina entra na sala, cumprimenta os alunos, pede que tirem o caderno de "Para Casa" e deixem sobre as mesas. Diz que vai passar algumas atividades no quadro para fazerem e enquanto isso vai verificar o dever de um por um, no caderno. Um aluno diz que não fez o dever. A professora responde: "Menino que não faz dever, eu vou mandar o nome pro Bolsa Escola, porque tá ganhando dinheiro muito fácil."

Regina passa no quadro uma lista de problemas, dizendo para os alunos copiarem. Assenta-se em sua mesa e começa a chamar as crianças individualmente para apresentarem seus deveres. Eventualmente, far pequenos comentários com os alunos a respeito dos deveres, pedindo capricho, atenção. Chama a atenção de alguns alunos que conversam. Depois de algum tempo, pergunta se todos já terminaram de copiar, para explicar. Uns dizem que sim, outros que não. Regina diz que vai esperar mais um pouco. Continua a chamar alunos para corrigir os deveres, pergunta novamente se já pode explicar, decide esperar mais um pouco. Até que diz:

- Vamos ver então como vocês vão resolver esse problema: "No jardim havia 246 rosas. Morreram 132 rosas. O jardineiro plantou mais 104 rosas. Quantas rosas ficaram no jardim?" Se morreram, aumentou ou diminuiu?

Alguns alunos em coro respondem: "Diminuiu".

- Então qual operação vou faz̧er? 
Alguns alunos respondem juntos: "Subtração".

- Depois o jardineiro plantou mais 104. Vai aumentar ou diminuir?

- Aumentar.

- Qual operação?

- Adição.

- Eu posso fazer tudo junto: $246-132+104$ ?

- Não!

- Não. Então vão ser duas operações: primeiro subtração, depois adição.

\section{Tá entendido?}

A professora explica de modo semelhante a resolução dos outros três problemas, então diz que os alunos podem resolvê-los no caderno. Assenta-se novamente para corrigir mais deveres. Depois de aproximadamente meia hora, inicia a correção dos problemas, chamando quatro crianças para resolvê-los no quadro. Quando os quatro terminam, diz. que está certo e pergunta se alguém tem dúvida. Ninguém responde, ela passa então a registrar no quadro o dever de casa a ser feito para o dia seguinte. Os deveres já corrigidos nos cadernos não são alvo de nenhum comentário geral com a turma.

(Diário de Campo, turma da escola Sol, 12-5-2004).

Assim, o tratamento dado ao dever de casa, na turma da escola Sol, não parece favorecer uma maior mobilização das crianças em relação a essa atividade escolar. As tarefas de casa são implicitamente desvalorizadas na própria dinâmica das aulas, no contexto de uma prática pedagógica centralizada na figura da professora e na expectativa de "obediência" do aluno, o qual é tratado de modo coercitivo, manifestando, muitas vezes, formas de resistência ou de indiferença aos valores escolares, como, por exemplo, a não realização dos deveres propostos ${ }^{21}$. Se, conforme apontam Carvalho, Nascimento e Paiva (2006, p. 354), “[...] a prática do dever de casa pode integrar o processo pedagógico de forma mais ou menos sistemática, significativa para os alunos e efetiva em termos de aprendizagem [...]", os dados obtidos na turma da escola Sol apontam para o lado menos favorável dessa relação.

É importante ressalvar que as diferenças e desigualdades identificadas entre as práticas pedagógicas nas turmas das escolas Lua, Estrela e Sol não podem ser associadas automaticamente à categoria administrativa do estabelecimento de ensino - isto é, escolas particulares e pública - e nem ao tipo de público atendido - camadas médias e camadas populares. Diferentes estudos vêm apontando o papel específico exercido, em contextos semelhantes (por exemplo, escolas de uma mesma rede de ensino ou que atendem a um 
público semelhante do ponto de vista socioeconômico), por diferentes práticas pedagógicas e modos de organização da dinâmica escolar, configurando os chamados efeito-professor e efeito-escola (DUBET, 2004; BRESSOUX, 2003). Esta pesquisa comparou práticas pedagógicas em relação ao dever de casa em apenas três escolas, em contextos sociais bastante distintos, não sendo possível, pelos procedimentos metodológicos adotados, generalizar as conclusões para todas as escolas que atuam no mesmo contexto. Também não é possível identificar até que ponto as características observadas na abordagem do dever de casa são resultantes da atuação específica de cada professora ou são comuns às demais turmas da mesma escola, uma vez que foi observada apenas uma turma em cada estabelecimento.

O que se pode afirmar, em suma, a partir da análise das práticas curriculares ligadas ao dever de casa nas escolas Lua, Estrela e Sol é que, somando-se às desigualdades no âmbito das famílias, e interagindo com elas, existem também, entre as ofertas escolares nas três turmas em questão, desigualdades significativas, as quais desfavorecem os mais desfavorecidos (DUBET, 2004). Nesse sentido, o dever de casa espelha, aqui, o fato de que a escola não apenas registra ou reproduz as desigualdades já existentes na sociedade, mas pode também alimentá-las com novos elementos de exclusão, através de seus modos de funcionamento, os quais podem exercer efeitos específicos na trajetória escolar e nas experiências dos indivíduos; efeitos esses que, se não são os principais responsáveis pelas desigualdades sociais, também não devem ser negligenciados nas análises (DUBET, 2003).

\section{CONSIDERAC̣̃̃ES FINAIS}

Neste trabalho, buscou-se evidenciar, a partir de dados de pesquisa empírica, desigualdades de diversas ordens, tanto no âmbito das famílias quanto no das escolas, que se espelham na prática social de prescrição e realização das "tarefas de casa". As características do texto limitam-no a uma problematização dessas desigualdades, sem que se possa aprofundar nas implicações dessa constatação. Entretanto, vale ressaltar, entre vários, alguns pontos que mereceriam maior discussão.

Inicialmente, tendo em vista o debate em torno da eficácia pedagógica dos deveres de casa, diante da questão da equidade educacional 
(CARVALHO, 2001; CARVALHO; BURITY, 2005), cabe lembrar que as desigualdades mencionadas neste texto, embora espelhadas na prática do dever de casa, não são engendradas diretamente por ela e a ela não se restringem. Em uma das entrevistas de pesquisa, Mariana, mãe de um aluno da escola Lua, afirmou que os deveres, em vez de significarem "mais" trabalho para os pais, representam "menos", uma vez que, se não existissem, ela própria precisaria elaborar atividades para orientar o estudo de seus filhos em casa. Diante de exemplos como esse, pode-se indagar se a mera supressão dos deveres significaria maior equidade, uma vez que os pais de diferentes grupos sociais continuariam lançando mão de estratégias diferentes - e necessariamente desiguais - para colocar seus filhos em melhores condições diante da competição escolar ${ }^{22}$. Percebe-se, assim, que não apenas as tarefas enviadas para casa, mas todo o processo educacional encontra-se remetido à desigualdade, em uma sociedade desigual, na qual os resultados escolares dependem fortemente de fatores extraescolares. Isso, evidentemente, não isenta a escola de sua responsabilidade no sentido de buscar minimizar, no âmbito da prática pedagógica, os efeitos dessa desigualdade. A respeito desse ponto cabem, certamente, discussões quanto aos critérios para a prescrição (ou não) dos deveres de casa e para sua abordagem em cada realidade educacional, considerando aspectos como a idade dos alunos, o seu grau de autonomia diante das tarefas escolares (por exemplo, autonomia de leitura e de escrita), as condições de realização do dever em casa, as condições da escola de oferecer suportes alternativos, entre outras.

Uma discussão de grande atualidade no Brasil, relacionada a esse ponto, é a da extensão da jornada escolar, na direção de uma escola de tempo integral. A ampliação do tempo na escola, preconizada pela atual LDB (BRASIL, 1996), tem se tornado realidade em um número crescente de escolas e municípios brasileiros (BRASIL, 2009). Nesse cenário, o tradicional dever de casa tem passado, em alguns casos, a ser realizado na própria escola, com acompanhamento de professores ou de monitores contratados para esse fim, como uma das alternativas para proporcionar às crianças, especialmente as de meios mais desfavorecidos, melhores condições de aprendizagem. Em outros casos, a extensão da jornada letiva, com a realização de diferentes atividades de cunho pedagógico, leva a indagar sobre o "lugar" dos deveres de casa numa escola de tempo integral, suscitando questões relativas à reorganização do currículo escolar e à redistribuição 
do trabalho educacional entre família e escola. Nessas diferentes situações, o dever de casa continua "espelhando" aspectos importantes do processo pedagógico e as questões a ele relativas não podem ser analisadas de modo desvinculado da teia de relações educacionais e sociais nas quais se inserem.

Outro ponto que merece aprofundamento é o que se refere às políticas de aproximação entre família e escola, as quais, muitas vezes, têm a finalidade de "educar" as famílias para que desempenhem a contento o papel educacional que a escola espera delas (CASTRO; REGAT'TIERI, 2009) - aí incluído o acompanhamento aos deveres. Iniciativas nesse sentido vão desde as tradicionais reuniões nas escolas até a publicação de cartilhas de orientação para os pais. Em que pese a importância da interação escolas-famílias, cabe lembrar o risco do "escolacentrismo" (SILVA, 2003), ou seja, de manter a lógica da escola como dominante, procurando moldar o funcionamento da casa e da família, sem se observar, da parte da instituição escolar, uma atitude equivalente - ouvir as famílias e propor-se mudanças a partir disso. Vale, também, indagar sobre os limites dessas políticas face às especificidades socioculturais de cada contexto familiar. Stein (1988, apud SILVA, 2003) propõe que, ao invés de tentar mudar os estilos de vida das famílias da classe operária de modo a ajustá-los aos padrões das classes médias, busque-se compreender e potencializar os pontos fortes do próprio modo de vida dessas famílias. Para o autor, os programas deveriam estimular, no caso das camadas populares, mais a orientação e o apoio - que seriam os pontos fortes de tais grupos - do que atividades sistematizadas de ensino por parte dos pais.

Finalmente, outra questão que mereceria aprofundamento é a da desigualdade de ofertas escolares, sabidamente perversa no caso brasileiro, no qual são especialmente verdadeiras as palavras de Dubet (2004, p. 545): “[...] aos diferentes grupos sociais são oferecidos sistemas escolares diferentes e desiguais [...]". Por um lado, é necessário e urgente envidar todos os esforços para construir maior igualdade de oportunidades educacionais - o que significa, especialmente, a luta pela qualidade de ensino na rede pública, considerando tanto as políticas públicas globais quanto os efeitos diferenciados de cada estabelecimento e, mesmo, da atuação de diferentes professores. Por outro lado não se pode, como lembra o autor, "[...] perder de vista que o fator de igualdade essencial é antes de tudo a redução das próprias desigualdades sociais. Nenhuma escola consegue, sozinha, produzir uma sociedade justa." (DUBET, 2004, p. 545). 


\section{REFERÊNCIAS}

ARIÈS, P. História social da criança e da família. 2. ed. Rio de Janeiro: LTC, 1981. BOURDIEU, P. (Org.). A miséria do mundo. 2. ed. Petrópolis: Vozes, 1998. BOURDIEU, P. Escritos de educação. 2. ed. Petrópolis: Vozes, 1999.

BRASIL. Ministério da Educação. Lei no 9.394, de 20 de dezembro de 1996. Estabelece as diretrizes e bases da educação nacional. Diário Oficial da República Federativa do Brasil, Brasília, DF, 23 dez. 1996. Seção 1.

BRASIL. Ministério da Educação. Educação integral/educação integrada e(m) tempo integral: concepções e práticas na educação brasileira. Mapeamento das experiências de jornada escolar ampliada no Brasil. Brasília: UFPR, UNB, UNIRIO, UFRJ, UERJ, UFMG, ULBRA, MEC, 2009. Disponível em: <http://portal.mec.gov.br.>

BRESSOUX, P. As pesquisas sobre o efeito-escola e o efeito-professor. Educaşão em revista, Belo Horizonte, n. 38, p. 17-88, dez. 2003.

CARVALHO, M. E. P. Rethinking family-school relations: a critique of parental involvement in schooling. Mahwah: Lawrence Erlbaum Associates, 2001.

CARVALHO, M. E. P. Escola como extensão da família ou família como extensão da escola? O dever de casa e as relações família-escola. Revista Brasileira de Educação, Rio de Janeiro, n. 25, p. 94-104, jan.-abr. 2004. http://dx.doi.org/10.1590/S1413-24782004000100009 CARVALHO, M. E. P.; BURITY, M. H. Dever de casa: visões de mães e professoras. In: REUNIÃO ANUAL DA ASSOCIAÇÃO NACIONAL DE PÓS-GRADUAÇÃO E PESQUISA EM EDUCAÇÃO - ANPED, 2005, Caxambu. Anais... Caxambu: ANPED, 2005. Disponível em: <http://www.anped.org.br/28/textos/gt14/gt141575int.rtf>.

CARVALHO, M. E. P.; NASCIMENTO, C. S.; PAIVA, C. M. O lugar do dever de casa na sala de aula. Olhar de professor, Ponta Grossa, v. 9, n. 2, p. 341-357, 2006. Disponível em: <www.uepg.br/olhardeprofessor/pdf/revista92_artigo09.pdf.>

CASTRO, J. M.; REGATTIERI, M. (Orgs.). Interação escola-família: subsídios para práticas escolares. Brasília: UNESCO/MEC, 2009.

CUNHA, M. I. P.; DURAND, J.-Y. Diferença e desigualdade. In: GARCÍA GARCÍA, J. L. et al. (Orgs.). Voces. Temas claves de la interculturalidad. Madrid: Editorial Complutense, 2007. Disponível em: <https://repositorium.sdum.uminho.pt/bitstream/1822/5373/3/ Diferença + e+Desigualdade.pdf $>$. Acesso em: 17 abr. 2007.

DESLANDES, R. (Org.). International perspectives on student outcomes and homework: family - school - community partnerships. New York: Routledge, 2009.

DUBET, F. A escola e a exclusão. Cadernos de Pesquisa, São Paulo, n. 119, p. 29-45, jul. 2003. DUBET, F. O que é uma escola justa? Cadernos de Pesquisa, São Paulo, n. 123, p. 539-555, set./dez. 2004.

FRANCO, C. et al. Qualidade e eqüidade em educação: reconsiderando o significado de "fatores intra-escolares". Disponível em: <http://www.econ.puc-rio.br/PDF/seminario/2007>. Acesso em: 03 jul. 2007.

GLASMAN, D. Le travail des élèves pour l'école em dehors de l'école. Chambery: Université de Savoie, 2005.

HENRIQUES, M. E. F. Os trabalhos de casa na escola do $1^{\circ}$ ciclo da Luz: estudo de caso. In: SILVA, P. (Org.). Escolas, familias e lares: um caleidoscópio de olhares. Porto: Profedições, 2007. 
LAHIRE, B. Sucesso escolar em meios populares: as razões do improvável. São Paulo: Ática, 1997. LAHIRE, B. Retratos sociológicos: disposições e variações individuais. Porto Alegre: Artmed, 2004. MEIRIEU, P. Os trabalhos de casa. Lisboa: Editorial Presença, 1998.

NOGUEIRA, M. A. Família e escola na contemporaneidade: os meandros de uma relação. In: REUNIÃO ANUAL DA ASSOCIAÇÃO NACIONAL DE PÓS-GRADUAÇÃO E PESQUISA EM EDUCAÇÃO - ANPED, 2005, Caxambu. Anais... Caxambu: ANPED, 2005. Disponível em: <http://www.anped.org.br/28/textos/gt14/gt14214int.rtf>

NOGUEIRA, M. A.; ABREU, R. C. Famílias populares e escola pública: uma relação dissonante. Educação em Revista, Belo Horizonte, n. 39, p. 41-60, jul. 2004.

PAULA, F. A. Lições, deveres, tarefas, para casa: velhas e novas prescrições para professoras. 2000. Dissertação (Mestrado)-Faculdade de Educação. Universidade Estadual de Campinas, Campinas, 2000.

PERRENOUD, P. Avaliação: da excelência à regulação das aprendizagens - entre duas lógicas. Porto Alegre: Artes Médicas Sul, 1999.

RAYOU, P. (Org.). Faire ses devoirs: enjeux cognitifs et sociaux d'une pratique ordinaire. Rennes: Presses Universitaires de Rennes, 2009. Collection "Paideia".

RESENDE, T. F. Dever de casa: questões em torno de um consenso. In: REUNIÃO ANUAL DA ANPED, 29., 2006, Caxambu. Anais...Caxambu: ANPEd, out. 2006a. Disponível em: <http:// www.anped.org.br>

RESENDE, T. F. Crianças e informação: papéis da família e da escola. Educação \& Realidade, Porto Alegre, v. 31, n. 2, p. 171-188, jul./dez. 2006b.

SILVA, P. Escola-Familia, uma relação armadilhada: interculturalidade e relações de poder. Porto: Edições Afrontamento, 2003.

THIN, D. Quartiers populaires: l'école et les familles. Lyon: Presses Universitaires de Lyon, 1998. THIN, D. Para uma análise das relações entre famílias populares e escola: confrontação entre lógicas socializadoras. Revista Brasileira de Educação, Rio de Janeiro, v. 11, n. 32, p. 211-225, maio/ago. 2006. http://dx.doi.org/10.1590/S1413-24782006000200002

VIANA, M. J. B. Longevidade escolar em famílias de camadas populares - algumas condições de possibilidade. In: NOGUEIRA, M. A.; ROMANELLI, G.; ZAGO, N. (Orgs.). Família e escola: trajetórias de escolarização em camadas médias e populares. Petrópolis: Vozes, 2000. p. $125-154$.

\section{NOTAS}

1 Este texto constitui uma versão ampliada do trabalho "Dever de casa, espelho de desigualdades", apresentado no XIII Congresso Brasileiro de Sociologia (Recife, 2007), no Grupo de Trabalho Educação e Sociedade. A autora agradece as contribuições dos presentes, especialmente do Prof. Cláudio Marques Nogueira e assume total responsabilidade pelo artigo e pelas ideias nele expressas. A pesquisa que deu origem ao texto foi financiada pelo CNPQ, pela FAPEMIG e pela PRPq/UFMG. 
${ }^{2}$ Esta caracterização socioeconômica baseia-se em aspectos como: ocupação e escolaridade dos pais e mães dos alunos (predominando, nas duas escolas, profissionais de nível superior); valor das anuidades praticadas pelos colégios (em torno de $\mathrm{R} \$ 5.000,00$ na época da pesquisa, ano de 2004); características dos domicílios visitados para as entrevistas; dados fornecidos pelas próprias escolas.

$3 \mathrm{Na}$ escola pública investigada predominam fortemente famílias cujos pais e mães têm ocupações manuais ou não especializadas, com baixa escolaridade (predominando o ensino fundamental, completo ou não), as quais moram em casas simples ou barracos, em um aglomerado da zona Sul de Belo Horizonte.

4 A intenção inicial era focalizar as escolas Lua e Sol, por serem geograficamente próximas e atenderem a públicos muito distintos do ponto de vista socioeconômico. Porém, a autorização para a pesquisa na escola Lua demorou a ser obtida. Iniciamos a investigação em outra escola privada na qual obtivemos autorização mais rapidamente (Estrela). Ao obtermos a autorização do colégio Lua, decidimos manter as duas escolas privadas no estudo, já que elas se localizam em diferentes regiões da cidade e possuem trajetórias distintas, interessando-nos verificar possíveis efeitos dessas nuances na relação família-escola.

5 As observações em sala de aula foram realizadas durante aproximadamente quatro meses do ano de 2004, com frequência de duas a três vezes por semana em cada turma e duração diária variável, buscando acompanhar a prática pedagógica como um todo, mas priorizando os momentos de abordagem (prescrição ou correção) do dever de casa.

${ }^{6}$ O questionário foi enviado, por meio dos próprios alunos, a todas as famílias que tinham filhos matriculados na $3^{\text {a }}$ série de cada escola: 173 famílias na escola Estrela, 39 na Lua e 65 na Sol. Obtiveram-se os seguintes índices de resposta: 55\% (Estrela), 51\% (Lua) e 66\% (Sol), perfazendo, no total, 160 questionários respondidos.

7 Para as entrevistas, foram selecionadas famílias que, ao responder ao questionário, declararam-se disponíveis para a nova etapa da pesquisa. Buscamos combinar critérios de modo a obter a maior diversificação possível dos sujeitos entrevistados. Alguns desses critérios: nível de formação e profissão dos pais; quem ajuda no dever de casa e quem respondeu ao questionário (pai/mãe); tipo de família (mono ou biparental, número de filhos, etc.); contratação ou não de profissional especializado para ajudar nos deveres; etc.

8 Não cabendo aqui um aprofundamento em torno das noções de "diferenças" e "desigualdades", utiliza-se a primeira para fazer referência a distinções ou dissemelhanças entre dois elementos postos em comparação e a segunda para designar a assimetria no acesso a direitos, ao poder e à riqueza, a recursos materiais ou simbólicos. Portanto, a ideia de desigualdade remete a hierarquizações sociais no interior das quais se encontram posições de superioridade e de inferioridade em relação à posse de determinado bem material ou simbólico. A configuração de uma diferença como desigualdade somente se explica dentro de um contexto no qual determinados bens são valorizados e distribuídos de modo desigual (para aprofundamento, ver CUNHA; DURAND, 2007).

${ }^{9}$ Os nomes de todos os sujeitos citados no texto foram substituídos por nomes fictícios. 
10 A não realização dos deveres de casa pelas crianças dessa turma era um problema constante, especialmente na disciplina de Língua Portuguesa, ministrada por Imaculada. Havia dias em que 15, 18 crianças não haviam feito o dever (turma de 32 alunos). Registrou-se um dia em que apenas 6 crianças tinham levado as tarefas de casa completas para a aula. 11 Segundo Bourdieu (1999), o capital cultural - conceito forjado pelo autor para fazer referência ao conjunto da bagagem cultural herdada da família, constituída por bens culturais socialmente dominantes - manifesta-se em três estados: o estado incorporado (na forma de disposições favoráveis a certas práticas culturais socialmente valorizadas), o estado objetivado (posse de bens culturais, como livros, instrumentos, etc.) e o estado institucionalizado (diplomas, certificações escolares).

$12 \mathrm{Na}$ época da pesquisa, o menino mora com a mãe e o pai em um apartamento bem montado e com decoração moderna, mas não luxuoso, na zona leste da cidade. O pai tem dois filhos adultos, do primeiro casamento, que não moram com ele; tem curso superior incompleto e é representante de vendas. A mãe é bacharel em Administração (curso que iniciou aos 28 anos, após separar-se do primeiro marido) e possui uma confecção, próxima ao prédio onde moram.

13 O Colégio Estrela tem se destacado, na cidade de Belo Horizonte, pelos resultados expressivos nos vestibulares e no Enem, sendo reconhecido como um colégio com alto nível de excelência acadêmica e de exigência em relação aos alunos.

14 Não cabe, aqui, uma digressão mais prolongada sobre as características e a proposta pedagógica de cada instituição. Vale destacar que os colégios Estrela e Lua são duas escolas privadas, laicas, de grande porte (ambas com número total de alunos acima de 2.000, da Educação Infantil ao Ensino Médio, na época de realização da pesquisa). Suas propostas pedagógicas, embora diferentes, têm em comum a busca de excelência acadêmica e desenvolvimento da criatividade, autonomia e espírito crítico, estimulando metodologias mais participativas, embora sem alterações significativas nas formas tradicionais de organização dos espaços e tempos escolares. A Sol é uma escola pública estadual, que atende aproximadamente 520 crianças nos anos iniciais do Ensino Fundamental (6 a 11 anos). Sua proposta pedagógica enfatiza um "ensino funcional e significativo", que forme um cidadão autônomo, desenvolvendo valores e atitudes considerados fundamentais para o trabalho, a realização pessoal e a vida em comunidade. A escola adota formas de enturmação relativamente flexíveis, associadas à ideia de ciclos de aprendizagem, porém as demais características da prática pedagógica observada podem ser relacionadas ao chamado "ensino tradicional".

15 No Manual do Estudante do Colégio Estrela encontram-se orientações gerais sobre a realização das tarefas de casa e indicações sobre o papel esperado da família em relação a elas. No Colégio Lua, o Manual do Professor apresenta orientações detalhadas sobre a prescrição dos deveres, incluindo aspectos como os objetivos, a frequência, a dosagem da quantidade de atividades e do nível de dificuldade, as formas de controle e de valorização do dever, as dinâmicas de correção, o seu uso como diagnóstico e recuperação paralela.

16 Evidentemente, havia diferenças entre as práticas pedagógicas nas turmas das escolas Lua e Estrela, embora os aspectos mais gerais fossem semelhantes. A decisão de, neste 
texto, caracterizá-las em conjunto e apresentar somente um trecho do diário de campo da escola Lua se deve às limitações de espaço.

17 Perrenoud (1999) analisa algumas características do trabalho escolar e indica recursos pessoais a serem mobilizados no desempenho desse trabalho: aplicação, perseverança, resistência ao tédio, conformismo, etc. Relacionamos tais recursos a disposições (maneiras mais ou menos duradouras de ver, pensar, sentir e agir) adquiridas ao longo dos percursos biográficos e das experiências socializadoras (LAHIRE, 2004).

18 Cabe ressaltar que o tipo de dever das escolas Lua e Estrela, se por um lado se pretende "criativo" e "desafiador", por outro lado pressupõe a existência desses "recursos pessoais" em um nível bastante elevado, na medida em que os enunciados tendem a ser mais elaborados, o nível de abstração maior, os deveres mais longos... Nesse contexto, tornam-se compreensíveis casos como o do aluno Renato, para quem o processo de socialização familiar não parece prover tais recursos na medida esperada.

${ }^{19}$ Não se teve acesso a nenhum documento que normatizasse a prescrição de deveres na Escola Sol. Entretanto, em entrevista com a supervisora, ela afirmou já ter sido combinado, em reuniões da equipe pedagógica, que o dever de casa deve ser dado diariamente.

20 Imaculada ministra Língua Portuguesa e Ciências e Regina, Matemática e Geo-História.

21 Cabe destacar que não somente os deveres de casa deixam de ser realizados nessa turma, sendo que, várias vezes, ao circular pelas carteiras, a pesquisadora constatou que as próprias atividades de aula ficavam incompletas nos cadernos. Além disso, o índice de deveres não realizados era muito maior na disciplina de Língua Portuguesa do que na de Matemática. Esses dados permitem presumir que, para além da suposta "omissão das famílias", alegada pelas professoras, haveria outros aspectos a serem considerados a fim de explicar os problemas em relação aos deveres.

22 Cabe mencionar, também, os estudos sobre a eficácia das escolas, que vêm dando contribuições para a discussão dos efeitos da prescrição de deveres sobre o desempenho escolar. Por exemplo, pesquisa desenvolvida por Franco et al. (2007) conclui que a prescrição e correção de deveres eleva o resultado escolar médio dos alunos e, embora beneficie mais aqueles de nível socioeconômico mais alto, é benéfica para 100\% dos estudantes. Mesmo que esse tipo de dado seja ainda polêmico, parece plausível supor que a supressão dos deveres em algumas escolas e em outras não, ao invés de trazer maior equidade, poderia representar um fator a mais de desigualdade.

Recebido: $19 / 10 / 2011$

Aprovado: 27/04/2012

\section{Contato:}

Universidade Federal de Minas Gerais Faculdade de Educação Departamento. de Ciências Aplicadas à Educação Av. Antônio Carlos, 6627 CEP $31270-901$ 